\title{
MIOCÁRDIO NÃO-COMPACTADO
}

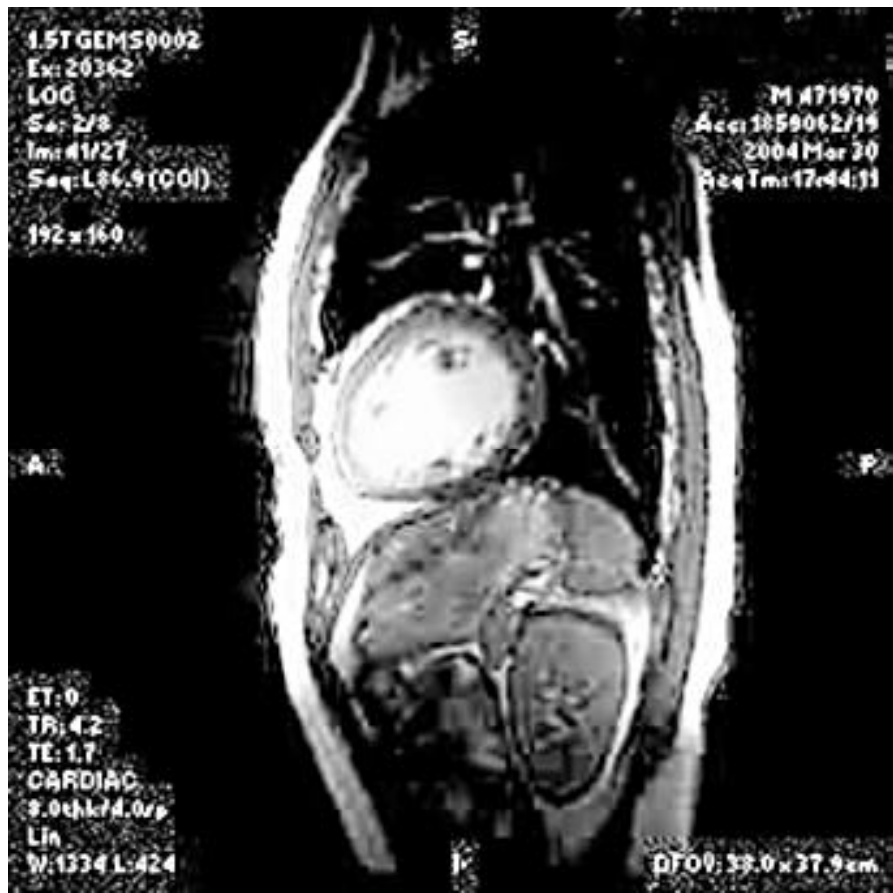

Paciente de 50 anos, hipertenso, procurou atendimento médico devido a cansaço aos esforços. O ecodopplercardiograma mostrou hipocontratilidade difusa (FE: $41 \%$ ), o que não foi encontrado em exames anteriores de rotina. A ressonância magnética revelou redução da função do ventrículo esquerdo (VE) e um padrão característico de miocárdio não-compactado. Normalmente, o VE exibe três trabeculações proeminentes. O encontro de mais de três trabeculações define o diagnóstico de miocárdio não-compactado.

Também chamada de hipertrabeculação do VE, miocárdio em esponja ou trabeculação isolada anormal de VE, esta doença foi descrita pela primeira vez em 1932, após necropsia. Até hoje, foram publicados 223 casos em todo o mundo, sendo apenas um no Brasil. Sua prevalência foi estimada em 0,05\% a 0,24\%, porém com o atual avanço dos métodos diagnósticos por imagem, esta prevalência tende a aumentar. A etiologia do miocárdio não-compactado não está bem definida, mas fatores genéticos heterogêneos parecem estar intimamente ligados à doença. Esta se associa ainda à insuficiência cardíaca, arritmias graves e eventos embólicos.

Assim, o miocárdio não-compactado é uma doença heterogênea, de prognóstico reservado e que, com o aprimoramento técnico dos métodos diagnósticos, maior número de diagnósticos poderão ser realizados

Giselle Helena de Paula Rodrigues, José Rodrigues Parga filho, Humberto Pierri, Joäo Batista Serro-Azul, Otávio Celso Eluf Gebara, Amit Nussbacher, Jairo Rays

\section{Unidade Clínica de Cardiogeriatria - InCor - hCFmusp}

\section{Referências}

|. Stöllberger C. Finsterer |. Left ventricular hypertrabeculation/noncompaction. | Am Soc Echocardiogr 2004; |7(1):91 - 100

2. Oechslin Em, Jost CHA, Rojas JR, Kaufmann PA, Jenni R. Long-term follow-up of 34 adults with isolated left ventricular noncompaction: a distinct cardiomyopathy with poor prognosis. J Am Coll Cardiol 2000; 36(2):493-500. 